\title{
Impact of Educational Program About Earphones Hazards and Healthy Hearing on Knowledge, Perception and Practices of Students in Zagazig University
}

\author{
Abeer Abd El-Aziz Mohamed Madian ${ }^{1} \quad$ Maha Mahmoud Abdelaziz $^{2} \quad$ Reda Elsaid Elbadwy Ezzat ${ }^{2}$ \\ 1.Assistant Professor of Community Health Nursing, Faculty of Nursing, Damanhour University, Egypt \\ 2.Lecturer of Community Health Nursing, Faculty of Nursing. Zagazig University, Egypt
}

\begin{abstract}
Background: The potential for hearing loss among younger generations is escalating every year. Likewise, the use of earphones has been thought to degrade a college student's academic performance. Hearing loss is an issue among the younger age group requires immediate attention. Aim: In light of this, this study was conducted in order to illustrate the impact of educational program about earphones hazards and healthy hearing on knowledge, perception and practices of students in Zagazig University. Design: A quasi-experimental pre/post-test design was adopted to carry out this study. Setting: the study was conducted at faculties affiliated to Zagazig University Subjects: The total number of the randomly selected students was 1532 Tools: data was collected using three tools; tool (I) A self-administered questionnaire entitled data about socio-demographic characteristic, tool (II):A students' knowledge, perception and practices questionnaire:, and tool (III) hearing loss designed questionnaire. Results: put on show that approximately less than two thirds (64\%) of studied students used earphones, there was a marked improvement in participant's knowledge, perception and practices regarding earphones hazards and healthy hearing post implementation of educational program, what's more, health problems were declined after implementation of the program, Conclusion: students had knowledge gaps regarding hazards of earphones and hearing health, the education program had positive impacts on knowledge, perception and practices of the studied students. Recommendations: Establishing national campaigns to promote knowledge about the hazards of earphones among adolescents and young adults and raising parents' awareness through national and social media to shed the light on hearing health.
\end{abstract}

Keywords: Earphones- Hazards- Impact - Students- Knowledge- perception- practices- educational programHealthy hearing.

DOI: $10.7176 / \mathrm{JHMN} / 67-04$

Publication date:October $31^{\text {st }} 2019$

\section{Introduction}

There has been a significant change from using radio and television to using mobile phones in people's life all over the world. There is no doubt about that individuals today use some type of wireless technology in everything they do. The damaging impacts of excessive noise pollution caused by stereo speakers have brought intense attention over the previous decade. (1) While using earphones all the time causes a lot of health problems, people can't imagine their life without using them now. ${ }^{(2)}$ Noisy hearing loss is deemed a major government and social health problem; adolescents were at danger of hearing impairment owing to excessive noise exposure in their life, but today they are at alarming hearing loss rates owing to excessive exposure of noise due to earphones. ${ }^{(3)}$

Using Personal Hearing Devices is popular and common, but the most harmful equipment seems to be headphones and earphones. Intensity and length of exposure of these instruments may result in permanent neural hearing loss of the bilateral sensor, particularly if listening for more than eight hours daily and over eighty five decibels can result in hearing loss. ${ }^{(4)}$ Additionally anyone who utilizes headphones for more than 90 minutes each day could endanger of hearing loss, and tinnitus that interferes with people's sleep, concentration,

Communication, relaxation capacity and increase chance of unaware of outside world. ${ }^{(5)}$ Furthermore , As persons carry them around from day to day, ear buds pick up dust, dirt, sweat and grime also can cause an increase in bacteria in the ear ${ }^{(6)}$ As well the presence of these bacteria can increase the risk of external ear canal inflammation known as otitis externa. It causes the ear to feel pain and pressure, also produces pus-like stinky discharges $^{\cdot(7,8,9)}$

WHO (2019) suggested that adolescents and young individuals should be better able to safeguard their hearing by maintaining the volume down on personal audio systems, wearing earplugs when visiting loud places. They can also restrict the amount of time invested in loud operations by taking brief hearing breaks and limiting the daily use of personal audio devices to less than an hour. They can monitor secure listening rates with the assistance of smartphone apps. They should also heed the warning signs of loss of hearing and receive frequent hearing check-ups. Governments also have a role to play by emerging and applying firm legislation on recreational noise, and by raising awareness of the dangers of hearing loss through public information campaigns. Parents, teachers and physicians can instruct young individuals about secure listening, while managers of entertainment 
executives can respect the safe noise rates set by their respective venues, use sound limiters, and offer earplugs and "chill out" rooms to clients. Manufacturers can design personal audio devices with security features and show data about safe listening on products and packaging. ${ }^{(10)}$

Community health nurse plays a major role in educating parents to ensure that their sibling limits the use of headphones and provides data on the hearing loss risk. Students should be informed of the volume to cover up outside noise, turn the volume up just enough to be able to hear music comfortably, but no more, not listen to music at more than $60 \%$ of the maximum volume, some devices have settings can use to limit the volume automatically and don't use earphones or headphones for more than an hour at a time and take a break for at least 5 minutes every hour. ${ }^{(11,12)}$

\section{Significance of the study:}

World Health Organization (2019) discovered that 43 million individuals aged 12-35 experienced hearing loss, and at least $50 \%$ of these instances were caused by the use of high volume earphones. As students always use private listening equipment with a dangerous pattern, they have a greater pattern of hearing loss score and needs more attention to provide interventions besides create strategies to improve hearing health score. $(10,13,14)$

Therefore, this study was aimed to illustrate the impact of educational program about earphones hazards and healthy hearing on knowledge, perception and practices of students in Zagazig University.

\section{Research hypothesis:-}

There is an improvement in the students' level of knowledge, perception and practices about earphones hazards and hearing health after application of the educational program.

\section{Material and Methods}

\subsection{Material}

2.1.1 Study design:

A quasi-experimental pre/post-test one group study design was assumed to carry out this study

\subsubsection{Study setting:}

The study was carried out in faculties affiliated to Zagazig University namely: Engineering, Education, and Sciences represented the practical faculties, and Literature, Law, and Commerce represented the theoretical faculties.

\subsubsection{Study subjects:}

Students who were enrolled in previously mentioned faculties in Zagazig University

\subsubsection{Inclusion criteria}

$>$ Males and females students.

$>$ Approved to participate in the research.

$>$ Over the age of 18 years.

$>$ Free from chronic diseases.

\subsubsection{Sampling technique:}

By using stratified sampling technique the following steps were conducted:-

$>$ All the faculties in the university of Zagazig (22 faculties) were divided into scientific and literature groups.

$>$ Six faculties $(25 \%)$ were selected randomly from each group to compose the faculties representing the study sample.

$>$ Seven- hundred and sixty six students were selected randomly from each group of faculties in both sexes: from each faculty there were approximately 256 students were randomly selected. Thus, the total number of sample was 1532 students.

\subsubsection{Sample size}

In academic year 2018-2019, the total number of the University students were 126932 , the sample size needed for the study estimated according to the following equation: ${ }^{(15)}$

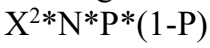

$\mathbf{n}=$

$$
\left(\mathrm{ME}^{2 *}(\mathrm{~N}-1)\right)+\left(\mathrm{X}^{2 * \mathrm{P} *(1-\mathrm{P}))}\right.
$$

- Where: $\mathrm{n}=$ sample size, $\mathrm{X}^{2}=$ Chi-square for the specified confidence level at 1 degree of freedom, $\mathrm{N}=$ population size, $\mathrm{P}=$ population proportion $(0.50), \mathrm{ME}=$ desired Margin of Error. So, the sample size was 1702 students at the beginning of the research then $10 \%$ of them excluded for a pilot study. Finally, 1532 undergraduate students from four academic years in the above mentioned selected faculties included in this study. 


\subsubsection{Study Tools:}

Data was collected using the following study tools:-

Tool (I): A self-administered questionnaire sheet: that constructed by researchers based on literature reviews and directed to all studied students, it entailed data about socio-demographic characteristic such as (age, gender, family income, residence, marital status, type of faculty, family members using earphones and sleeping hours.

- For students using earphones; type of materials heard, reasons of earphone using, common time and setting of earphone using.

- In addition to, health problems among students as, headache, nervousness, anxiety, sleep disturbance and temporary tinnitus.

Tool (II): A student's knowledge, perception and practices questionnaire sheet:

This tool was established by the researchers after literature review and directed to students using earphone only, it was used to collect data regarding the following:-

- Students' knowledge related to earphones hazards and healthy hearing, it composed of 12 questions that covered students'knowledge as, definitions of earphones, noisy, hearing loss, risk factor for hearing loss, negative effect of noisy, negative effect of using earphone, signs of hearing loss and criteria of selection of earphone type. For each knowledge item, a score of 2 was given for the correct answer, while a score of 0 was given for the wrong or don't know answer. So, the total scores for the questionnaire were 24 grades. These scores were summed and were converted into a percent score.

$$
\begin{aligned}
& \text { Unsatisfactory }(0-12)<50 \% \\
& \text { Satisfactory }(12-24)>50 \%
\end{aligned}
$$

-Perception of students regarding using earphone was developed by Rekha et al., 2011. ${ }^{(16)}$.The instrument consists of 7 items, it included questions as if student always being in noisy settings, if hearing loss caused by noise can be prevented, using cotton in the ears can protect people from hearing loss due to loud noises, ringing in the ears is an early warning sign for overexposure to potentially hazardous sound levels, if students saying "huh" or "what" or asking for repeats, if other people voices sounding muffled or mumbled" and having to turn the volume up on TVs or radios were signs of hearing loss or not . Responses were measured on a 3-point Likert rating scale. Items were anchored from (1) Never to (2) sometimes (3) Always. The total score ranged from 7 to 21 . The higher scores mean higher perception. These scores were summed and were converted into a percent score.

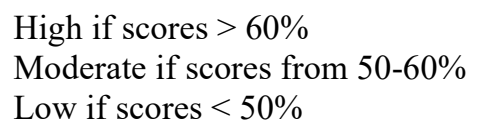

- Students' practices regarding using of earphone, it included data about preferable sound levels of listening, duration of listening to music through earphone ,mode of listening to music , how to purchase good quality earphone, proper time for using earphone and cleaning methods of it. This part was assessed on 6 frequency rating questions. The response of each practice question was scored as 2 for "correct adherent level and 0 for incorrect adherent level. A total score for practices related to using of earphone was obtained by summing the scores of these 6 questions which ranged from $0-12$, these scores were summed and were converted into a percent score as follows:

$$
\begin{aligned}
& \text { Good adherent level }(\geq 6 \text { points }) \geq 50 \% \\
& \text { Poor adherent level }(<6)<50 \%
\end{aligned}
$$

Tool (III): Hearing loss designed questionnaire sheet based on questionnaire that was developed by Arlinger, $2003{ }^{(17)}$ and was used to measure hearing loss. The instrument consists of 17 items as present of problem over hearing the telephone, trouble when two people talk at same time, frequently turn the volume of TV up too high, strain to understand conversation, have trouble hearing in a noisy back ground, asking people to repeat themselves, see people you talk to seem to mumble (or not speak clearly), misunderstand what others are saying and respond inappropriately, feel slowed down by a hearing problem, have a hearing problem cause difficulty when listening to TV or radio, fail to hear someone talking from behind you, have trouble hearing the alarm clock, not hear the doorbell or telephone, can't hear soft sounds such as birds singing, find that people speak too fast (on TV, friends, doctors), understand men's voices better than women's and lastly, need to turn toward the person speaking or cup the ear to understand what is being said. Responses were measured by the following; No" answers were coded as 1 and "Yes" answers were coded as 2. The range of scores was between 17 and 34, with a higher score indicating a severe hearing loss. Audiometry test was used and the results showed by using ROC curve analysis to evaluate these 17- items of hearing loss, the area under the curve (AUC) was 0.605 (95\% CI: $0.587-0.825 ; \mathrm{P}=0.001)$.

\subsection{Methods}

\subsubsection{Administrative process}

$>$ Official approval was obtained by submission of an official letter issued from the Dean of the Faculty of Nursing at Zagazig University to the Deans of the six faculties after randomly selected to conduct the study. 


\subsubsection{Development of study tools}

$>$ Tools (I) and(II) were developed by the researchers after reviewing recent literature in order to collect the required data from the studied students

$>$ Validity of the tools were done by three faculties staff nursing experts in the field of community health nursing specialties and medical staff of audiology who reviewed the tool for clarity, relevance, comprehensiveness and applicability. The panel ascertained the face and content validity of the tools. The reliability was done by Cronbach's Alpha coefficient test which revealed that each of these tools consisted of relatively homogenous items as indicated high reliability. The reliability of the tool I was 0.804 and tool II was 0.912 .

\subsubsection{Pilot study}

A pilot study was carried out on $10 \%$ students of the study sample from selected faculty to test applicability, feasibility and clarity of the tools of data collection, and estimating the time needed for assessment, and intervention.

\subsubsection{Data collection}

$>$ The data was collected from the students in selected faculties at suitable time using tool I, II, III after a brief explanation of the purpose and the nature of the research.

$>$ Data was collected during the academic years $2018-2019$.

$>$ The researchers reviewed the educational schedule of the selected faculties, after that the researchers selected the class rooms randomly through practical sections or theoretical lectures. Data collection was performed through the following stages:-

\section{1- Preparatory phase:}

\section{2- Preparation of sessions:}

3- Educational program' sessions were prepared by the researchers for the students. The content of the sessions was based on review of literature.

\section{$>$ The objectives of the sessions:}

$>$ - The objectives of educational program were to encourage voluntary changes in

$>$ behavior and practices favorable to hearing health. This improvement in practices could be attained by improving knowledge and perception.

$>\quad$ Educational program strategies

A. Program methods:

Different methods of instructions were adopted as brain storming, group discussion, case

$>\quad$ study and role play.

$>$ B- Teaching aids:

$>$ Different aids were used to facilitate and illustrate teaching such as posters, handouts, and real good quality of earphone

$>$ 2-Implementation phase:

$>\quad$ This phase started with pretest to assess the students' knowledge concerning earphone and hearing health before starting the program. The Questionnaire sheets (tools I, II, III) were distributed to the students by the researchers. Time needed to answer this sheet was 20-25 minutes then the implementation of the planned educational program. A time schedule suitable for students was developed to conduct the program that included; date, place, topic, time and duration of each session. The students were divided into 30 groups; each group included 25-35 students. The educational program designed for this study has been implemented through 30 sessions. Each researcher responsible about 10 sessions. Therefore, educational program was implemented through the sessions for each group. Each session lasted approximately 60 minutes. Firstly, discussion of the session objectives and content were dedicated. Then, time was available for student's participation and interaction. Different methods of instructions and teaching aids mentioned before were used.

\section{Content of the educational program}

1- High risk persons for hearing loss

2- Risks of earphone overuse.

3- Increase in students intention to use hearing protection

4- Negative effect of noise

5- Signs of hearing loss

6- Criteria of good quality earphone

7- Preferable sound level

8- Duration of listening to music through earphone

9- Mode listening to music

10- Changes in perception and practice related to earphone use 


\section{1- Ways to prevent hearing loss}

\section{3- Evaluation phase:}

Post-test was done immediately after the completion of the educational program to evaluate the change in the students' knowledge and secondly three months after its completion to determine the impact of educational program on students' perception and practices about using earphones and healthy hearing.

\subsubsection{Statistical analysis:}

After collecting data, responses to each questionnaire item were entered into the statistical analysis using SPSS 16.0 statistical software package. The level of significance ( $p$-value) was set at $\leq 0.05$. The following statistical tests were used:-

\section{Descriptive statistics:}

Descriptive statistics were used for representation and tabulation of data. Continuous variables were represented as means \pm SD while categorical variables were represented as frequencies and percentages. The mean percent scores for knowledge, perceptions and practices were calculated.

\section{Analysis of numeric data:}

- Chi square test $\left(\mathrm{X}^{2}\right)$ was used for testing the relationship between categorical variables.

- Paired t-test was used to compare between sample means for quantitative data with normal distribution.

- Graphs were done for data visualization by using Microsoft Excel program.

- ROC curve analysis to evaluate the 17 -item hearing loss questionnaire

\subsubsection{Ethical considerations:}

$>$ Permission was obtained to collect the data from the previous faculties after explanation of the aim of the study and assure them that collected data will be used only for the study purpose.

$>$ The purpose of the study was clarified to students and oral informed consent was obtained to participate in the study. Confidentiality and anonymity of subjects; as well as their withdrawal right from the research at any time were assured without any consequences.

\section{Results}

Table (1): Distribution of the studied students in line with socio- demographic characteristics.

\begin{tabular}{|c|c|c|}
\hline Items & $\begin{array}{c}\mathbf{N} \\
(\mathrm{N}=1532)\end{array}$ & $\%$ \\
\hline Age: & Mean \pm S.D & \\
\hline $\begin{array}{ll} & \text { Gender: } \\
\text { - } & \text { Male } \\
\text { - } & \text { Female } \\
\end{array}$ & $\begin{array}{c}453 \\
1079 \\
\end{array}$ & $\begin{array}{l}29.6 \\
70.4\end{array}$ \\
\hline $\begin{array}{ll} & \text { Family income: } \\
\text { - } & \text { Sufficient } \\
\text { - } & \text { Sufficient and store } \\
\text { - } & \text { Insufficient } \\
\text { - } & \text { Insufficient and debt }\end{array}$ & $\begin{array}{l}726 \\
177 \\
520 \\
109\end{array}$ & $\begin{array}{c}47.4 \\
11.6 \\
33.9 \\
7.1\end{array}$ \\
\hline $\begin{array}{ll}\text { Marital status: } \\
\text { - } & \text { Single } \\
\text { - } & \text { Married } \\
\end{array}$ & $\begin{array}{c}1415 \\
117 \\
\end{array}$ & $\begin{array}{c}92.4 \\
7.6 \\
\end{array}$ \\
\hline $\begin{array}{ll} & \text { Residence: } \\
\text { - } & \text { Rural } \\
\text { - } & \text { Urban }\end{array}$ & $\begin{array}{l}842 \\
690\end{array}$ & $\begin{array}{l}55.0 \\
45.0\end{array}$ \\
\hline $\begin{array}{l}\text { Faculties : } \\
\text { - } \quad \text { Theoretical } \\
\text { - } \quad \text { Practical }\end{array}$ & $\begin{array}{l}766 \\
766\end{array}$ & $\begin{array}{l}50.0 \\
50.0\end{array}$ \\
\hline $\begin{array}{l}\text { Family members use an earphone: } \\
\text { - Parents } \\
\text { - Brothers \& Sisters } \\
\text { - No one } \\
\text { - All }\end{array}$ & $\begin{array}{c}112 \\
1034 \\
94 \\
292\end{array}$ & $\begin{array}{c}7.3 \\
67.5 \\
6.1 \\
19.1\end{array}$ \\
\hline
\end{tabular}

Table (1): Presents that, the mean age of the studied participants was $20.8 \pm 1.6$ year. As regard to gender and social status of the studied participants, $70.4 \%$ and $92.4 \%$ of them were female and single, respectively. Also, $47.4 \%$ of the studied participants their family income was sufficient. As to residence, $55 \%$ of the participants under study residing in rural areas. In relation to the faculty of the studied participants, it was found that, $50 \%$ of 
them were theoretical and $50 \%$ of them were practical. Moreover, $67.5 \%$ of the participants their brothers \& sisters use an earphone. Also, the mean of the sleeping hours was $6.9 \pm 1.9$.

Figure (1): Distribution of the studied students in line with earphone use $(\mathbf{N}=1532)$

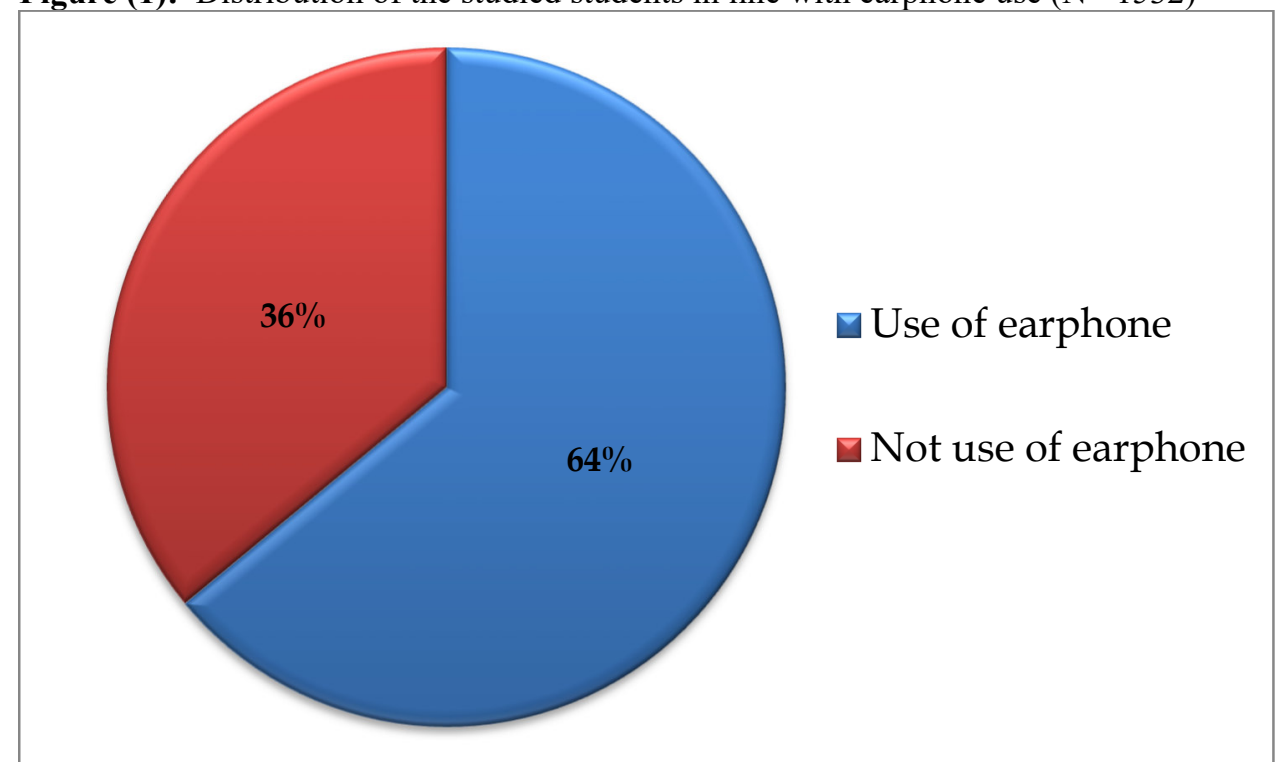

Figure 1: Display that approximately less than two thirds (64\%) of studied students used earphones compared to more than one third (36\%) didn't use it

Figure (2): Distribution of the studied students in line with types of materials heard through earphones $(\mathbf{N}=981)$.

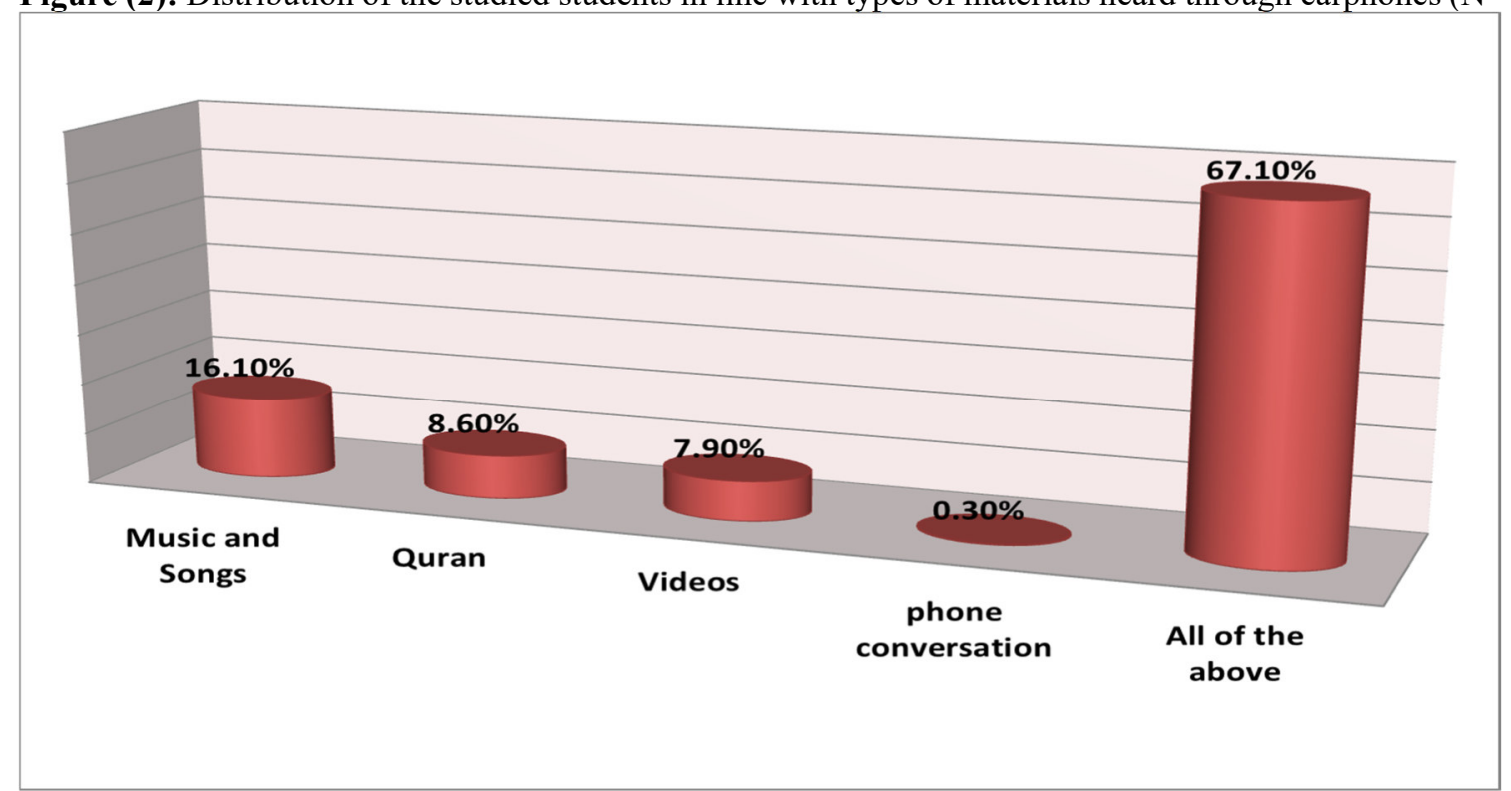

Figure (2): Illustrates that, $67.1 \%$ of the studied students were listening to all types of materials through earphone. Also, $16.1 \%$ of them were listening to music and songs through earphone. 
Figure (3): Distribution of the studied students in line with their reasons of earphone using $(\mathbf{N}=981)$

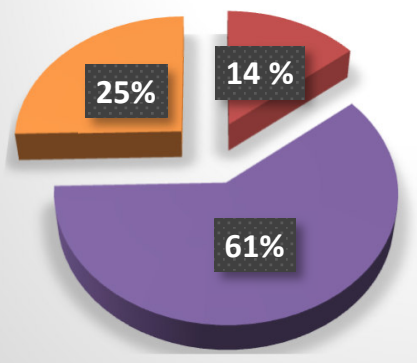

- Fashion and Like others

To hear a loud voice without disturb others

To be isolated with myself

Figure (3): Indicates that, $61 \%$ of the studied students were using the earphone to hear aloud voice without disturb others. While, one quarter of $(25 \%)$ students were using the earphone to be isolated with themselves and less than one fifth (14\%) of them were using the earphone to be fashion and like others.

Figure (4): Distribution of the studied students in line with their common time (of earphone using $(\mathbf{N}=981)$

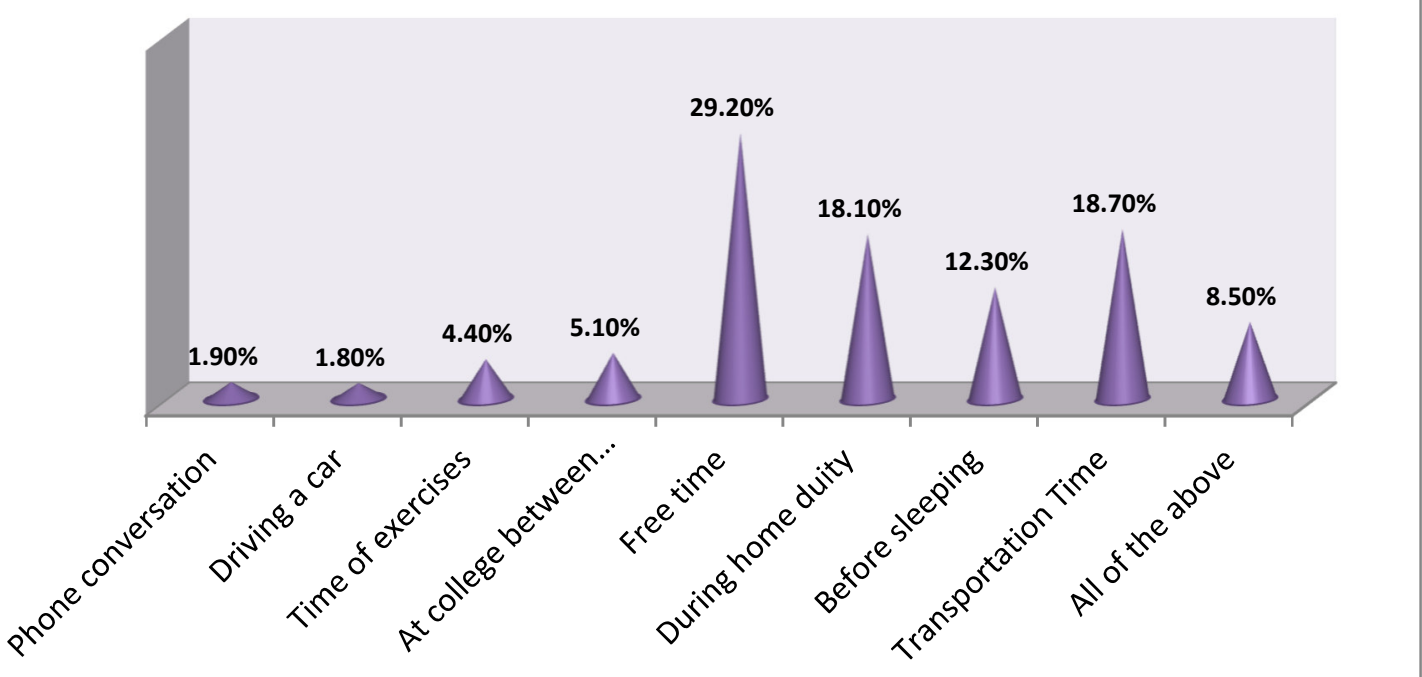

Figure (4): Reveals that, $29.2 \%$ of the studied participants were using the earphone at free time and relaxation. Also, $18.7 \%$ and $18.1 \%$ of them were using the earphone at transportation time and during homework or home duties, respectively.

Figure (5): Distribution of the studied students in line with their knowledge regarding earphones hazards and healthy hearing pre/post educational program $(\mathbf{N}=981)$.

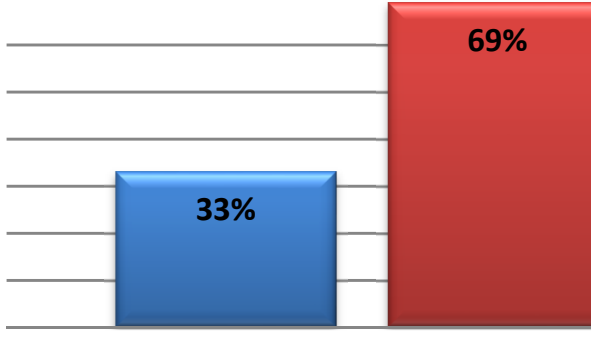

Satisfaction knowledge

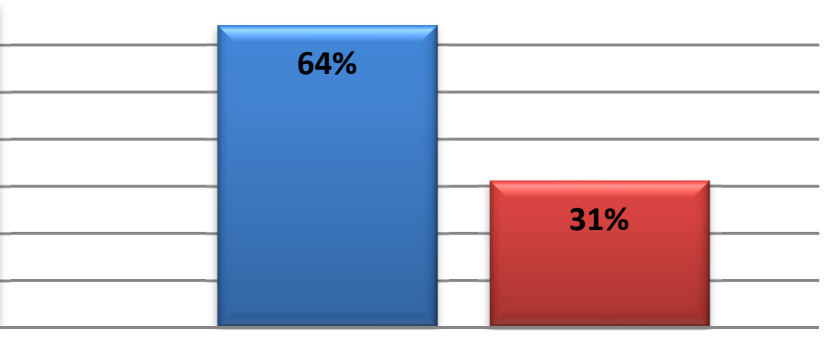

Unsatisfaction Knowledge

圆Pre 圆Post

Figure (5): Confirms that, 64\% of the studied students had unsatisfactory knowledge about earphones hazards and healthy hearing pre educational program. Even though, 69\% of them had satisfactory knowledge post educational program. 
Table (2): Compare means between studied students regarding their knowledge about earphones hazards and healthy hearing pre/post educational program.

\begin{tabular}{|l|c|c|c|c|}
\hline \multicolumn{1}{|c|}{ Items } & $\begin{array}{c}\text { Means score } \\
\text { Pre }\end{array}$ & $\begin{array}{c}\text { Means score } \\
\text { Post }\end{array}$ & T paired test & P. value \\
\hline Definitions(earphones, noisy, hearing loss) & 0.94 & 1.67 & 9.33 & $.001^{*}$ \\
\hline High risk persons for hearing loss & 0.86 & 1.90 & 8.04 & $.002^{*}$ \\
\hline Negative effect of noisy & 1.10 & 1.76 & 7.71 & $.003^{*}$ \\
\hline Negative effect of using earphone & 1.15 & 1.842 & 6.49 & $.002^{*}$ \\
\hline Signs of hearing loss & 1.20 & 1.64 & 8.412 & $.001^{*}$ \\
\hline Criteria of good quality of earphone & 0.84 & 1.57 & 7.31 & $.003^{*}$ \\
\hline Total & $\mathbf{5 . 6 4}$ & $\mathbf{1 1 . 3 4 0}$ & $\mathbf{1 1 . 3 4 2}$ &. $\mathbf{0 0 0}$ \\
\hline
\end{tabular}

Table (2): Shows that, there was a marked improvement in participant's knowledge regarding earphones hazards and healthy hearing post implementation of educational program with highly statistically significant difference $(\mathrm{P}=<0.05)$ between pre and post- implementation of program.

Figure (6): Distribution of the studied students in line with their preferable sound levels of listening pre/post educational program.

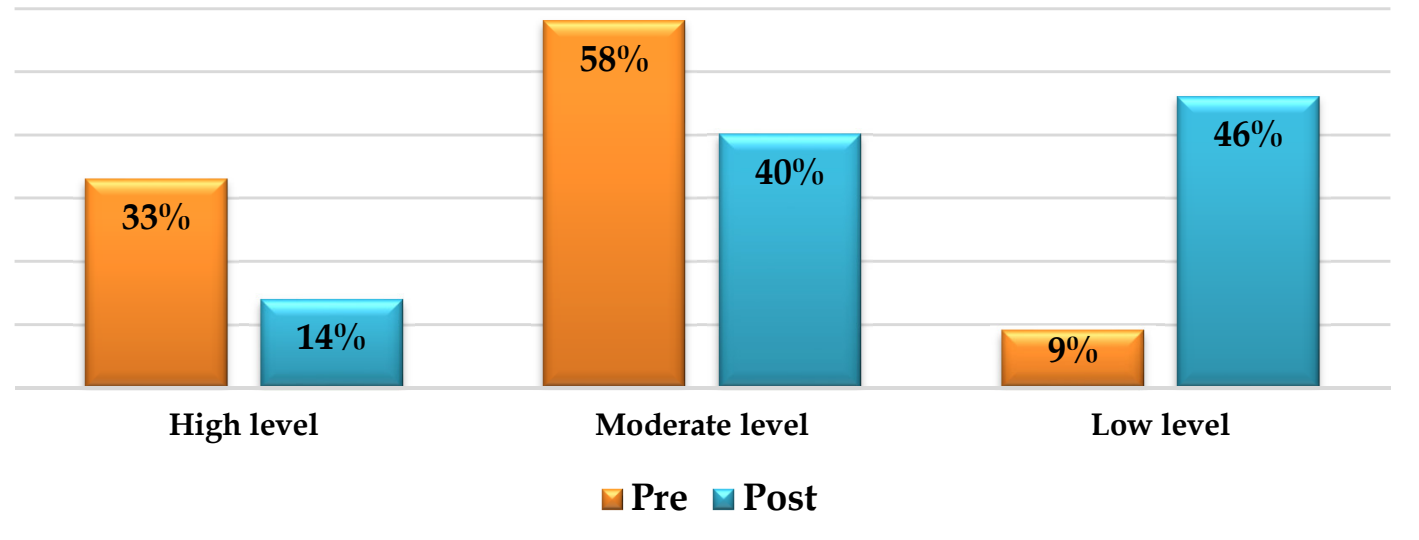

Figure (6): Shows that, more than half (58\%) of the studied students had moderate level of preferable sound of listening pre educational program compared to $40 \%$ of them post educational program. Moreover, one third (33\%) of the studied students had high level of preferable sound pre educational program decreased to less than one fifth $(14 \%)$ of students post educational program.

Figure (7): Distribution of studied students regarding duration of listening to music through earphone pre/ post educational program.

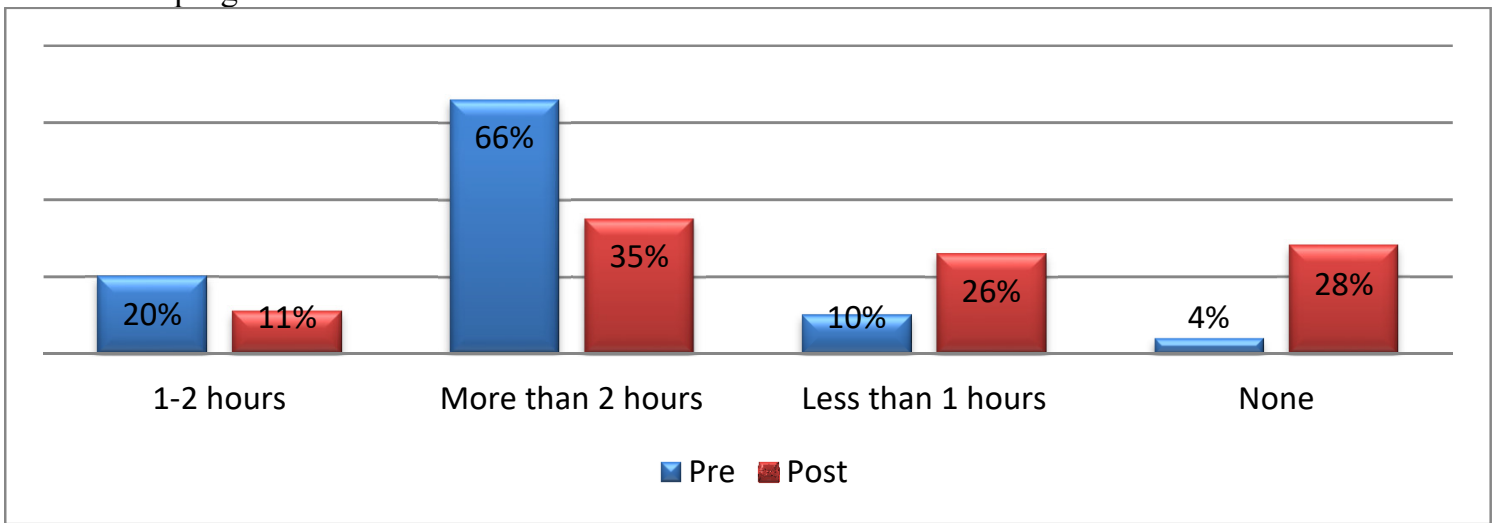

Figure (7): Spectacles that, $66 \%$ of the studied students were listening to music through earphone more than 2 hours pre educational program. While decreased to $35 \%$ of them were listening to music through earphone more than 2 hours post educational program. 
Figure (8): Distribution of studied students regarding mode of listening to music pre/ post educational program.

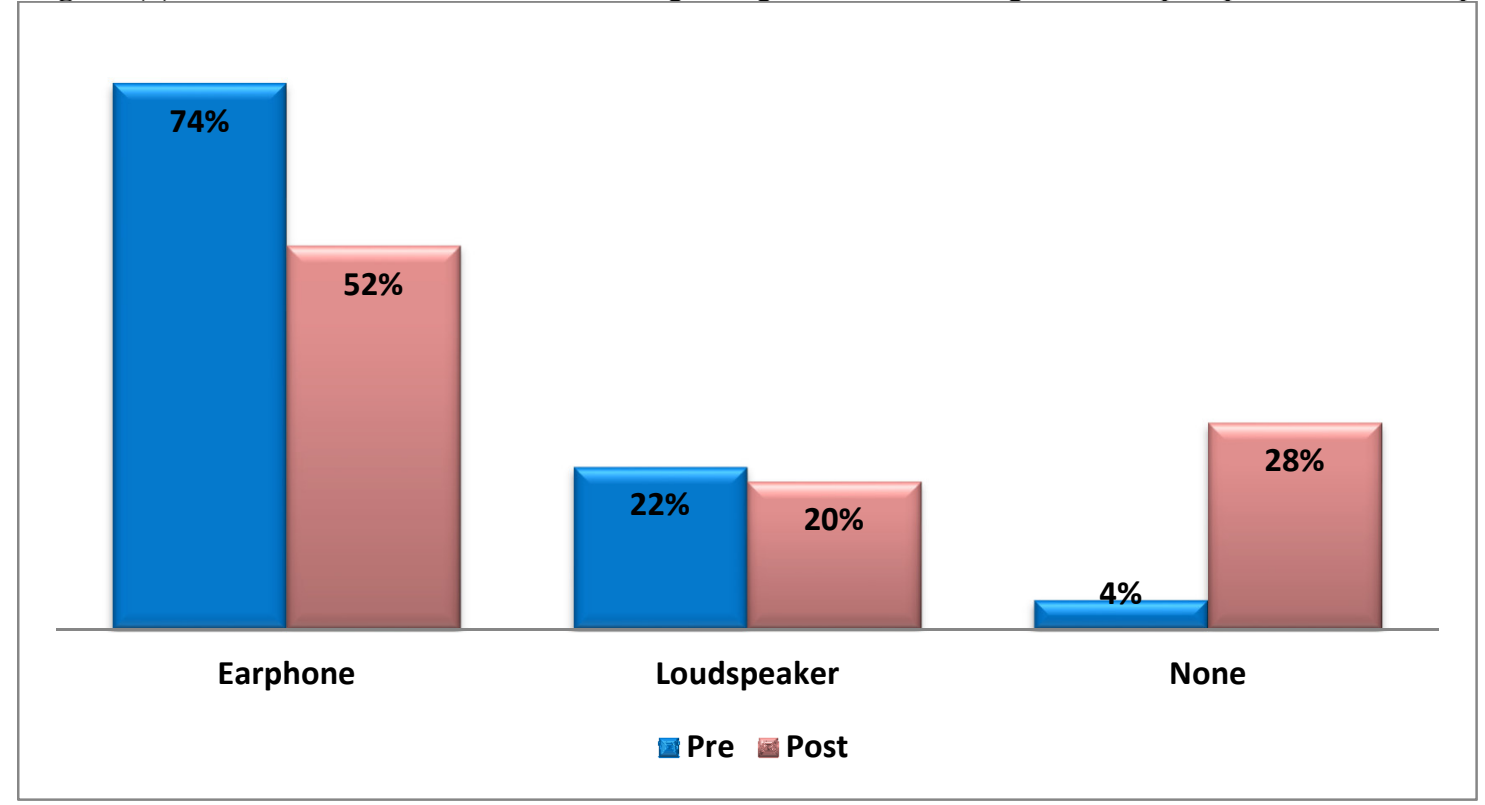

Figure (8): Shows that, about three quarters (74\%) of the studied students were listening to music through earphone pre educational program. While post educational program, decreased to slightly more than half $(52 \%)$ of them were listening to music through earphone.

Table (3): Compare means between studied students regarding their perception regarding using earphones pre/post educational program. $(\mathrm{N}=981)$

\begin{tabular}{|c|c|c|c|c|}
\hline Items & $\begin{array}{l}\text { Means } \\
\text { score } \\
\text { Pre }\end{array}$ & $\begin{array}{l}\text { Means } \\
\text { score } \\
\text { Post }\end{array}$ & $\begin{array}{l}\text { T paired } \\
\text { test }\end{array}$ & $\begin{array}{l}P \text { P. } \\
\text { value }\end{array}$ \\
\hline Are you often staying in noisy settings? & 1.975 & 3.361 & 7.310 & $.003^{*}$ \\
\hline $\begin{array}{l}\text { Do you think that hearing loss caused by noise can be } \\
\text { prevented? }\end{array}$ & 2.056 & 3.610 & 8.614 & $.002 *$ \\
\hline $\begin{array}{l}\text { Do you think that using cotton in the ears can protect people } \\
\text { from hearing loss due to loud noises? }\end{array}$ & 2.213 & 3.841 & 9.315 & $.004^{*}$ \\
\hline $\begin{array}{l}\text { Do you think ringing in the ears is a warning sign for } \\
\text { overexposure to potentially hazardous sound }\end{array}$ & 1.674 & 3.120 & 11.789 & $.000^{*}$ \\
\hline $\begin{array}{l}\text { Are you say "huh," "what," or ask for repeats because you } \\
\text { do not hear others clearly? }\end{array}$ & 1.864 & 3.250 & 7.200 & $.003 *$ \\
\hline Are other people's voice, sound muffled, or mumbled to you? & 2.647 & 3.451 & 8.647 & $.002 *$ \\
\hline $\begin{array}{l}\text { Is having to turn up the volume on TV's or radio's a sign of } \\
\text { hearing loss? }\end{array}$ & 2.147 & 3.258 & 9.012 & $.001 *$ \\
\hline
\end{tabular}

Table (3): Shows that, there was a marked improvement in participant's perception regarding using earphones post implementation of educational program with highly statistically significant difference at $(\mathrm{P}=<0.05)$ between pre and post- implementation of educational program. 
Table (4): Measuring of hearing loss among the studied students pre/post educational program

\begin{tabular}{|c|c|c|c|c|}
\hline $\begin{array}{l}\text { \#Audiometry test } \\
\text { The 17- items hearing loss questionnaire }\end{array}$ & $\begin{array}{l}\text { Pre } \\
(\mathbf{N} \\
=981)\end{array}$ & $\begin{array}{l}\text { Post } \\
(\mathbf{N} \\
=981)\end{array}$ & $\mathbf{X}^{2}$ & $\begin{array}{l}\mathbf{P} \\
\text { value }\end{array}$ \\
\hline Do you have a problem of hearing over the telephone? & $71 \%$ & $41 \%$ & 5.31 & $.010^{*}$ \\
\hline $\begin{array}{l}\text { Do you have trouble following the conversation when two or more } \\
\text { people are talking at the same time? }\end{array}$ & $66 \%$ & $49 \%$ & 6.27 & $.009 *$ \\
\hline Do people complain that you turn the TV volume up too high? & $59 \%$ & $36 \%$ & 6.35 & $.008^{*}$ \\
\hline Do you have to strain to understand conversation? & $60 \%$ & $46 \%$ & 5.78 & $.012 *$ \\
\hline Do you have trouble hearing in a noisy background? & $71 \%$ & $39 \%$ & 8.30 & $.000^{*}$ \\
\hline Do you find yourself asking people to repeat themselves? & $65 \%$ & $45 \%$ & 4.36 & $.014^{*}$ \\
\hline Do people you talk to seem to mumble (or not speak clearly)? & $51 \%$ & $38 \%$ & 9.31 & $.000^{*}$ \\
\hline $\begin{array}{l}\text { Do you misunderstand what others are saying and respond } \\
\text { inappropriately? }\end{array}$ & $49 \%$ & $40 \%$ & 7.48 & $.001 *$ \\
\hline Do you feel slowed down by a hearing problem? & $73 \%$ & $60 \%$ & 6.04 & $.009^{*}$ \\
\hline $\begin{array}{l}\text { Does a hearing problem cause you difficulty when listening to TV or } \\
\text { radio? }\end{array}$ & $51 \%$ & $31 \%$ & 7.94 & $.001 *$ \\
\hline Do you fail to hear someone talking from behind you? & $43 \%$ & $29 \%$ & 8.37 & $.000^{*}$ \\
\hline Do you have trouble hearing your alarm clock? & $47 \%$ & $37 \%$ & 4.11 & $.014^{*}$ \\
\hline Do you not hear the doorbell or telephone? & $56 \%$ & $42 \%$ & 3.99 & $.019 *$ \\
\hline Can you no longer hear soft sounds such as birds singing? & $39 \%$ & $34 \%$ & 4.76 & $.010^{*}$ \\
\hline Do you find that people speak too fast (on TV, friends, doctors)? & $64 \%$ & $55 \%$ & 5.23 & $.011 *$ \\
\hline Do you understand men's voices better than women's? & $67 \%$ & $61 \%$ & 4.01 & $.018^{*}$ \\
\hline $\begin{array}{l}\text { Do you need to turn toward the person speaking or cup your ear to } \\
\text { understand what is being said? }\end{array}$ & $47 \%$ & $37 \%$ & 8.89 & $.000 *$ \\
\hline
\end{tabular}

\#ROC curve analysis to evaluate the 17-item hearing loss part of the questionnaire

Table (4): shows that, there was a marked decreased in participant's hearing loss post implementation of educational program with highly statistically significant difference at $(\mathrm{P}=<0.05)$ between pre and postimplementation of educational program.

Table (5): Compare between percentage distributions of health problems related using headphone pre/ post educational program.

\begin{tabular}{|l|c|c|c||c|}
\hline \multicolumn{1}{|c|}{ Health problems } & $\begin{array}{c}\text { Pre } \\
(\mathbf{N}=981)\end{array}$ & $\begin{array}{c}\text { Post } \\
(\mathbf{N = 9 8 1 )}\end{array}$ & $\mathbf{X}^{\mathbf{2}}$ & P. value \\
\hline Sleep disturbance & $78 \%$ & $41 \%$ & 4.17 & $.005^{*}$ \\
\hline Nervousness & $76 \%$ & $46 \%$ & 4.19 & $.009^{*}$ \\
\hline Headache & $71 \%$ & $41 \%$ & 4.62 & $.009^{*}$ \\
\hline Anxiety & $69 \%$ & $38 \%$ & 3.55 & $.007^{*}$ \\
\hline Pain in ear & $66 \%$ & $34 \%$ & 5.31 & $.003^{*}$ \\
\hline Temporary Tinnitus & $49 \%$ & $22 \%$ & 4.69 & $.005^{*}$ \\
\hline
\end{tabular}

Table (5): Shows that, there was a marked reduced in participant's health problems related using headphone post implementation of educational program with highly statistically significant difference at $(\mathrm{P}=<0.05)$ between pre and post- implementation of educational program.

\section{Discussion}

Earphones or ear buds in telephony early days are a couple of tiny hearing instruments intended to be worn over the ears of a user on or around the head. Earphones are very tiny, fitted in the outer ear straight, but not inserted into the ear canal. Earphones are electro-acoustic transducers that convert an electrical signal to a corresponding sound in the user's ear. These days' most young people use portable music listening devices (PLDs) with earphones, due to the convenience of listening to music anytime and anywhere. However, they are not aware about risk of damage to hearing due to excessive use of personal listening devices with earphones. ${ }^{(18)}$

Most music enthusiasts are unaware of the danger of sensorineural loss of hearing. Chronic exposure to highintensity sounds can result in continuous hearing losses of 85 decibels or higher on average. Most individuals are used to listen to high-volume with headphones or earphones or boost their quantities after some moment of extended use; which may indicate an on-going permanent hearing loss in those individuals. ${ }^{(19)}$

Moreover, there is a growing concern as regards the hearing health of the young adults, because now a day the usage of personal listening devices and mobile phones with earphone or headphones has increased 
extremely in youth. Long term use of these devices with high intensity of sound could bring irreversible damage to auditory system. (20) Consequently, this study aimed to illustrate the impact of educational program about earphones hazards and healthy hearing on knowledge, perception and practices of students in Zagazig University.

The current study gives a clear picture of 1532 students in different faculties in Zagazig University, most of them were single females, the average age of the students in the sample was $20.8($ standard deviation $=1.6)$. The result of this study indicated the high prevalence of earphone use $(64 \%)$ among the students. This is reliable with the results of recent studies conducted by Wandadi et al. (2014) ${ }^{(21)}$ in Iranian students and Basu etal(2019) ${ }^{(22)}$ in Delhi, India.

The results of the current study similarly presented that more than two thirds $(67.1 \%)$ of the studied students were listening to all types of materials as music, videos, Quran, and phone conversations through earphone. These results go in line with study done in $\operatorname{Iran}(2019)^{(23)}$ to assess prevalence and pattern of using headphones among high school students and stated that most of the participants had listened to music on their cellphones $(81.7 \%)$, laptops $(10.8 \%)$, computers $(4.1 \%)$, and $\mathrm{mp} 3$ players $(3.4 \%)$. With regard to the reasons for using earphones, $89.6 \%$ of the participants used earphones for listening to music, $4.6 \%$ used for listening to lectures, $4.2 \%$ used for English learning, and 1.6\% used for game playing.

At the present time, adolescents and young adults consciously expose themselves to loud noise or music for long periods of time and they are ignorant of its consequence. Existing study revealed that about less than two thirds of students had unsatisfactory knowledge about earphones hazards and healthy hearing pre educational program but there was a marked improvement in their knowledge post implementation of educational program with highly statistically significant difference between pre and post implementation of program. These results acquainted with study done by Santana etal (2016) (24) who reported that most students had prior knowledge of the harmful effect of amplified music on hearing and even then, some indicated inadequate habits. The educational lecture showed significant improved in some of the aspects investigated, reflecting a need to structure continuous actions towards hearing loss prevention.

Hearing damage caused by leisure activities with loud noise has been growing noticeably in young persons, causing concern among researchers. Exposure to high sound pressure levels in leisure activities has been placing at risk the hearing of youth throughout the world. ${ }^{(25,26)}$ The prevalence of listening to loud or very loud music differs across countries. For instance, the corresponding rate among high school students in Iran was described to be $50 \%{ }^{(27)}$. The prevalence of listening to loud or very loud music was estimated to be $37.4 \%$ and $35 \%$ in studies in Brazil and USA, respectively ${ }^{(28,29)}$. The observed differences could be clarified by the students' age and other socio-demographic factors including cultural differences.

According to the American Speech Language Hearing Association (ASHA), 61\% of American teenagers have personal stereos, while $51 \%$ of students in American high schools prefer high volumes, as adults tend to use more moderate volumes. ${ }^{(30)}$. Nearly one third of students in the present study had high level of preferable sound of listening pre educational program compared to less than one fifth had low level of preferable sound levels of listening post educational program. Moreover, two thirds of students were listening to music through earphone more than 2 hours pre educational program while decreased to about one third post educational program.

Several studies were done in different countries ${ }^{(31,32,33)}$ have also specified the improper use of earphones (e.g., listening to loud music, using earphones for lengthy period of time, and not getting breaks while using earphones to listen to music) among adolescents and youth. The incorrect use of earphones among these collections can be due to the lack of awareness about the hazards of listening to loud music. Since there is an upward trend in the use of earphones and personal listening devices ${ }^{(34,35)}$ because there is an upward trend among adolescents and youth in the use of earphones and private hearing equipment, it is therefore essential to improve consciousness to tackle the inaccurate use of earphones among the young population. ${ }^{(36)}$

In addition, the current study revealed headache, nervousness, anxiety, sleep disturbance, pain in ear and temporary tinnitus were common among students, it is critical to implement environmental interventions and training programs to raise the awareness about this issues among these populations. Even so, it seems that raising awareness alone is not sufficient for changing the attitude and performance in this age group. ${ }^{(37)}$ Results of these study incongruent with this point of view in which there was a marked reduced in participant's health problems associated with using headphone post implementation of educational program with highly statistically significant difference. On the other hand, these results compatible with some studies had done on using earphones by students for longer time and reported some hearing problems. like pain in ear, temporary hearing loss, headache, sleeping disturbance, earache and complain of ringing or humming sound in absence of external sound known as tinnitus which indicates premature hearing problem. ${ }^{(28,38)}$

Harshitha et al (2017) ${ }^{(39)}$ accompanied a survey on prevalence and effect of earphone usage among adolescents. This survey tested several areas like dependence on earphones, its psychological impact on individuals and health issues people experienced after using headphones. Sample consisted of men and women between the age group of 15 to 24 years. The results indicated that almost all the individuals use earphones daily for at least 12 hours per day. It was also evident that majority of users had at least 1 pairs of earphones and many other users 
own more than 4 pairs of earphones, they look for sound quality, size, and affordability when they decide to buy a pair of earphones. This may be attributed to their awareness of the criteria for good quality earphones.

Most youth had preceding knowledge about the harmful effects of high-intensity music on hearing. However, this knowledge did not lead to changes in these youths' perception with regard to exposure to amplified music, since they remained with inadequate habits and attitudes a finding of this study dissimilar to previous study ${ }^{(40)}$, there was a marked improvement in participant's perception regarding using earphone post implementation of educational program with highly statistically significant difference .

In another study ${ }^{(41)}$, most students reported knowing that high-intensity noise may lead to hearing loss. However, only some of the participants reported not knowing how to protect their hearing, or not being concerned about preventing the effects of exposure to high-intensity music. The results of the ROC curve $(0.605)$ which compares hearing loss measured by the designed questionnaire with an audiometric test as the standard test, suggested an acceptable predictive power of the designed questionnaire to identify hearing loss. It was observed from this study that there was a marked decreased in participant's hearing loss post implementation of educational program with highly statistically significant difference between pre and post- implementation of educational program. In some countries, for example in Canada, hearing loss was mainly measured using self-reported data. Using the designed questionnaire to assess hearing loss may be better than using self-reported hearing loss. This is because some studies have already demonstrated that self-reported hearing loss may underestimate hearing loss problem, especially in mild and moderate hearing loss and among the youth ${ }^{(42)}$. In addition, some studies reported a significant difference between the results of audiometric tests and self-reported hearing loss ${ }^{(43,44)}$.

Lastly, personal listening devices (PLDs) enable users to listen to music without interruption for long periods of time and at rates that may pose a danger of hearing loss. Listeners who use ear bud earphones are more at danger because they do not attenuate elevated concentrations of ambient noise and require increased volume for acoustic pleasure. Unfortunately not much attention is being given to the increasing trend of prolonged exposure to noisy environment and excessive use of earphones in the younger generation. Based on that, it is believed that educative actions should start in early elementary school since this is a period in which children with a typical development do not oppose to social, educational, and/or familiar rules, which makes the awareness of health risks and maintenance of healthy habits a successful action. ${ }^{(45)}$

\section{Conclusion and Recommendations}

Results of current study reflected that, despite most students having prior knowledge about earphones hazards and hearing damages caused by high-intensity music, some still reported inadequate habits. The educational program led to significant changes in some of the elements investigated, reflecting a need to structure continuous actions for the youth, aiming at the prevention of hearing loss, mainly when considering college students. Nevertheless, it's an issue of concern to note that many students perceived the threat of uncontrolled use of earphones and strong perceived benefits of seeking educational programs. Based on findings of the present study, it could be concluded that results of this study confirmed the hypothesis as University students who engage in education program demonstrate improved level of knowledge, perception and practices. Therefore, it was clearly that implementation of education program had positive impacts on knowledge, perceptions and practices of faculty students.

\section{Based on the current study findings the following recommendations could be made:}

1- Establishing national campaigns to promote knowledge about the hazards of earphones among adolescents and young adults.

4- Raising parents' awareness through national and social media to shed the light on hearing health.

5- Contents related to hearing health should be including in educational curricula of schools and universities. The inclusion of the school and the family in educative actions and the continuity of these actions are fundamental to effective changes in habits and attitudes in children and adolescents.

6- The higher hearing loss score among earphones users requires further attention in order to implement interventions and develop strategies for improving students' awareness and attitude towards the use of personal listening devices.

\section{Acknowledgments}

The authors would like to greatly acknowledge the deans of faculties in Zagazig University for their cooperation. They also wish to thank all the students for their valuable cooperation and participation in this study.

\section{References}

1. Thomas, C., et al. (2019). Hearing Loss in Adults: Differential Diagnosis and Treatment. ; 100 (2):98-108. [Online]. Available: https://www.aafp.org/afp/2019/0715/p98.html. (2019 Jul 15)

2. Shivani, D. (2018). Harmful effects of earphones: How your headphones and earphones are damaging your health. [Online].Available : At https://www.lifealth.com/wellness/healthy-living/harmful-effects-of- 
earphones-how-your-headphones-and-earphones-are-damaging-your-health-sd/79423/ (Jun 2018)

3. Joy, V. (2019). Healthy Hearing; How to prevent hearing loss from headphones or ear buds. PMCID: PMC4754097.PMID: 26929674.( May 29, 2019)

4. Asghar, M., et al. (2018). Prevalence and Pattern of Using Headphones and Its Relationship with Hearing Loss among Students .Health Scope; 8 (1).e65901.Published Online: (September 1, 2018). DOI: 10.5812/jhealthscope.65901

5. Keppler, H., et al. (2015). Hearing in young adults. Part II: The effects of recreational noise exposure. Noise Health; 17 (78):245-52. [Online]. Available: http://www.noiseandhealth.org/text.asp?2015/17/78/245/165026

6. American Academy of Family Physicians. (2019) Clinical preventive services recommendation: hearing. [Online].Available: https://www.aafp.org/patient-care/clinical-recommendations/all/hearing.html (May 6, 2019).

7. Heather, T. (2018) .Ear buds is the Cause of Ear Infections? What You Should Know. Doi: 10.26616/NIOSHPUB2013142. (June 23, 2018).

8. World Health Organization. (2019). The hearing screening experiences and practices. doi: 10.26616/NIOSHPUB2015184. (15 Mar 2019).

9. Stephen, E., et al. (2018). Headphone listening habits, hearing thresholds and listening levels in Swedish adolescents with severe to profound HL and adolescents with normal hearing. 57 (10):730-36. https://doi.org/10.1080/14992027.2018.1461938 (27 Apr 2018).

10. World Health Organization WHO. (2019). 1.1 billion people at risk of hearing loss. At https://www.who.int/mediacentre/news/releases/2015/ear-care/en

11. Stephen, W., et al. (2017). Headphone listening habits and hearing thresholds in Swedish adolescents, 88 (19):125-32| PMCID: PMC5501022. PMID: 28615542.

12. Nasim, K., et al. (2018). The hearing screening experiences and practices of primary health care nurses: Indications for referral based on high-risk factors and community views about hearing loss. Afr J Prim Health Care Fam Med. 10(1): 1848. doi: 10.4102/phcfm. v10i1.1848 (10 Oct 2018).

13. Mehdi, W., et al. (2014). Effects of listening to music over headphones, the musical, prevalence of using personal music player and listening habit in students. 1 (2):3032. DOI: 10.30476/jrsr.2014.41051 (June 2014).

14. Sullivan, M. (2017). Noise Health. From Wikipedia, the free encyclopedia. Fast Company.; 19(88): $125-132$. doi: 10.4103/nah.NAH_65_16.(2017 May).

15. Krejcie \& Morgan. (1970). "Determining Sample Size for Research Activities". Educational and Psychological Measurement. 30. pp. 607-10.

16. Rekha, T., et al. (2011). Perceptions and practices regarding use of personal listening devices among medical students in coastal South India. Noise and Health; 13(54), 329- 32. [Online]. Available: http://www.noiseandhealth.org/text.asp?2011/13/54/329/85500

17. Arlinger, S. (2003). Negative consequences of uncorrected hearing loss-a review. International journal of $\begin{array}{llll}\text { audiology, } & \text { 22(2); } & \text { [Online].Available: }\end{array}$ http://static1.squarespace.com/static/555364cbe4b05a323bd3d58f/t/56ccbf7c3c44d8670dbd41f1/145625894 0917

18. Breinbauer, HA., et al. (2012). Output capabilities of personal music players and assessment of preferred listening levels of test subjects: Outlining recommendations for preventing music-induced HL. Laryngoscope, 122:2549-2555.

19. Feder, K., etal. (2013). Audiometric thresholds and portable digital audio player user listening habits. Int J Audiol; 52(9): 606- 16.doi:10.3109/14992027.2013.798687.

20. Serra, MR., et al. (2014). Hearing and loud music exposure in 14-15 years old adolescents. Noise Health; 16(72):320-30. doi: 10.4103/1463-1741.140512.

21. Wandadi, M., et al. (2014). Prevalence of using personal music player and listening habit in students. J Rehabil Sci Res.; 1(2):30-2. [Online]. Available: https://www.researchgate.net/publication/265293457_(20 July2014).

22. Basu, S., et al. (2019). Knowledge and practices related to the use of personal audio devices and associated health risks among medical students in Delhi. Noise Health. DOI: 10.4103/jehp.jehp_308_18 (February 28, 2019)

23. Mahammadpoorasl, A., et al. (2019). Prevalence and pattern of using headphones and its relationship with hearing loss among students. Health Scope: 8 (1); [Online]. Available: http://jhealthscope.com/en/articles/65901.html.DOI;10.5812/jhealthscope.65901

24. Santana, BA., et al. (2016). Prevention in a school environment of hearing loss due to leisure noise. Audiol Commun Res.; 21: e1641. [Online]. Available: http://dx.doi.org/10.1590/2317-6431-2015-1641

25. Biassoni, EC., et al. (2014). Hearing and loud music exposure in a group of adolescents at the ages 14-15 and retested at 17-18. Noise Health; 16(72):331-41. http://dx.doi.org/10.4103/1463-1741.140515 3. 
26. Lee, GJC., et al. (2014). The music listening preferences and habits of youths in Singapore and its relation to leisure noise-induced hearing loss. Singapore Med J.; 55(2):72-7. [Online]. Available: http://dx.doi.org/10.11622/smedj.2014018.

27. Ansari, H., et al. (2014). Pattern of use of earphone and music player devices among Iranian adolescents. Int J Prev Med.; 5(6):776-81. [PubMed: 25013698].

28. Herrera, S., et al. (2016). Amplified music with headphones and its implications on hearing health in teens. Int Tinnitus J.; 20(1):42-7. doi: 10.5935/0946- 5448.20160008. [PubMed: 27488993].

29. Torre, P. (2008). Young adults' use and output level settings of personal music systems. Ear Hear; 29(5):7919. doi:10.1097/AUD.0b013e31817e7409. [PubMed: 18633323].

30. Portnuff, CD. (2016). Reducing the risk of music-induced hearing loss from overuse of portable listening devices: Understanding the problems and establishing strategies for improving awareness in adolescents. Adolesc Health Med Ther;10(7):27-35 DOI: 10.2147/AHMT.S74103

31. Sulaiman, AH., et al. (2015). Hearing risk among young personal listening device users: Effects at high-frequency and extended high-frequency audiogram thresholds. J Int Adv Otol; 11(2):104-9 doi: 10.5152/iao.2015.699

32. Jiang, W., et al. (2016). Daily music exposure dose and hearing problems using personal listening devices in adolescents and young adults: A systematic review. Int J Audiol; 55 (4):197-205. doi: $10.3109 / 14992027.2015 .1122237$.

33. Vogel, I., et al. (2009). Adolescents and MP3 players: too many risks, too few precautions. Pediatrics; 123(6): e953-8. doi: 10.1542/peds.2008-3179. [PubMed: 19482747]

34. Gilles, A., et al. (2013). Epidemiology of noise-induced tinnitus and the attitudes and beliefs towards noise and hearing protection in adolescents. PLoSOne.; 8(7). e70297. doi: 10.1371/journal.pone.0070297. [PubMed: 23894638]. [PubMed Central: PMC3722160].

35. DelGiacco, AM., et al. (2015). Education and knowledge of noise exposure, hearing loss, and hearing conservation in college students. Contemp Issues Commun Sci Disord.; 42:88. DOI: 10.1044/cicsd 42 S 88.

36. Schwebel, DC., et al. (2012). Distraction and pedestrian safety: How talking on the phone, texting, and listening to music impact crossing the street. Accid Anal Prev ;45:266-71. doi: 10.1016/j.aap.2011.07.011. Epub 2011 Aug 9.

37. Zhao, F., et al. (2011). Music exposure and hearing health education: A review of knowledge, attitude, and behaviour in adolescents and young adults. Health Educ J.; 71(6):709-24. doi: 10.1177/0017896911422780.

38. Gonçalves, CL. Et al. (2014). Audio logical findings in young users of headphones. Rev CEFAC. 2014;16(4): 1097-108.DOI: http://dx.doi.org/10.1590/1982- 0216201422412

39. Harshitha, S., et al. (2017). A survey on prevalence and effect of earphone usage among adolescents, Int $\mathrm{J}$ Appl Res; 3(12):438-42. [Online]. Available: https://www.academia.edu/35506934/A_survey

40. Sliwinska, K., et al. (2012). A. Noise-induced hearing loss. Noise Health; 14(61):274-80. doi: 10.4103/14631741.104893.

41. Alexandra, T., et al (2012). Listen up: wearing headphones can endanger life, study finds. [Online]. Available: website: https://www.theguardian.com/technology/2012/jan/16/headphones-can-endanger-life-study.

42. Lin, FR., et al. (2011). Hearing loss prevalence and risk factors among older adults in the United States. J Gerontol a Biol Sci Med Sci.; 66(5):582-90. doi: 10.1093/gerona/glr002. [PubMed: 21357188]. [PubMed Central: PMC3074958]

43. Feder, KP, et al. (2017). Prevalence of hearing loss among a representative sample of Canadian children and adolescents, 3 to 19 years of age. Ear Hear; 38(1):7-20. doi: 10.1097/AUD.0000000000000345. [PubMed: 27556530]. [PubMed Central: PMC5181131].

44. Feder, K., et al. (2015). Prevalence of hearing loss among Canadians aged 20 to 79: Audiometric results from the 2012/2013 Canadian Health Measures Survey. Health Rep.; 26(7):18-25. [PubMed: 26177043]

45. Neelima, G., et al. (2014). Assessment of knowledge of harmful effects and exposure to recreational music in college students of Delhi: a cross sectional exploratory study. Indian J Otolaryngol Head Neck Surg.; 66(3): 254-259. doi: 10.1007/s12070-013-0671-5. 